\title{
Efficacy of Unmanned Helicopter in Rainwater Removal from Cherry
}

\section{Canopies}

\author{
Jianfeng Zhou ${ }^{1}$, Lav R. Khot ${ }^{1, *}$, Troy Peters ${ }^{1}$, Matthew D. Whiting ${ }^{2}$, Qin Zhang ${ }^{1}$, David
} Granatstein $^{3}$

\footnotetext{
${ }^{1}$ Center for Precision and Automated Agricultural Systems, Department of Biological Systems Engineering, Washington State University, Prosser, WA 99350; ${ }^{2}$ Department of Horticulture, Washington State University, Prosser, WA 99350; ${ }^{3}$ Tree Fruit Research and Extension Center, Washington State University, Wenatchee, WA 98801. *Corresponding author, (e-mail: lav.khot@wsu.edu)
}

\section{Abstract:}

Rain-induced fruit cracking causes significant economic loss for fresh market sweet cherry growers annually. To prevent cherry cracking, timely removal of rainwater from fruit is the key. This study evaluated the efficacy of an unmanned middle-size helicopter to remove rainwater from Y-trellised cherry canopies. Helicopter downwash in hover at four altitudes, with and without a payload, was quantified with six anemometers deployed in tree canopies. Results showed that payload and altitude significantly affected hover downwash, which was greater at higher altitude of $7.6 \mathrm{~m}$ above ground level (AGL) than lower altitude of $4.9 \mathrm{~m}$ AGL with payload. In the absence of payload, hover downwash peaked at the altitude of $6.1 \mathrm{~m}$ AGL. In the efficacy study, 5.0-mm rainwater was applied to cherry canopies by a rainfall simulation system, followed by the helicopter flying over canopies at three altitudes (4.9, 5.5 and $6.1 \mathrm{~m}$ AGL), two travel speeds (1.3 and 2.7 m. s$\left.{ }^{-1}\right)$ and with or without payload. Rainwater removal at bottom (1.1 $\mathrm{m})$, middle $(1.9 \mathrm{~m})$ and top $(2.7 \mathrm{~m})$ of the canopies was calculated based on the change of leaf wetness of target canopies in 10 min after rain. Overall, helicopter with payload flying $2.7 \mathrm{~m} . \mathrm{s}^{-1}$ 
at $6.1 \mathrm{~m}$ AGL removed significantly more rainwater (96.3\%) from top section of canopies than groups without treatment $(71.2 \%)$ and compared to other payload and travel speed conditions.

27 Results also confirmed that the unmanned helicopter could provide sufficient downwash to 28 remove rainwater effectively from bottom and middle canopy sections.

Keywords: Sweet cherry; fruit cracking; unmanned helicopter; downwash; canopy wetness

\section{Introduction}

Fresh-market sweet cherry (Prunus avium L.) is a profitable crop for growers in the

Pacific Northwest region of the U.S. In 2014, growers in Washington State produced ca. 217,000 tons of fresh-market sweet cherries with a farm gate value of approx. 488 million U.S. dollars (USDA-NASS, 2015). However, annually, rain-induced cherry fruit cracking results in substantial economic loss to growers through reduced marketability of cracked fruit. Rainfall, Long, 2015). maturing fruit through either tree roots or rainwater on the fruit cuticle (Considine and Brown,

42 1981; Simon, 2006). Therefore, the key methods of preventing cherry cracking are to reduce

43 potential uptake of rainwater or remove rainwater from cherry fruit surface quickly and

44 effectively during and after rainfall events. Existing fruit cracking prevention solutions include use of canopy covers, chemical application, and rainwater removal by machines. The methods of using canopy covers (Børve et al., 2003; Thomidis and Exadaktylou, 2013; Meland et al., 2014)

47 and mineral-based chemical (e.g. $\mathrm{CaCl}_{2}$ ) applications prior to rainfall (Jedlow and Schrader, 
48 2005; Simon, 2006) are effective and currently used in commercial farm operations. A new

49 hydrophobic food-grade polymer product was recently introduced and shows promise in

50 prevention of fruit cracking (Kaiser et al., 2014). However, the cost of installation of canopy

51 covers limits their adoption to growing regions that face high rain pressure during harvest.

52 Meanwhile, in the case of spray applications, multiple spray passes are needed to keep fruit

53 protected due to the significant washout of chemical by rainwater (Kafle et. al, 2016). Also,

54 spray residue on the fruit surface has an unsightly appearance (Jedlow and Schrader, 2005)

55 reducing marketability of the fresh-market produce.

56 Mechanical methods for removing rainwater use either the crosswind from an orchard

57 air-blast sprayer or the downwash of manned helicopters (Jedlow and Schrader, 2005)

58 immediately after rain events. Empty air-blast sprayers can generate strong crosswind and blow

59 rainwater off tree canopies when driving through orchard alleyways. Zhou et al. (2016) gave a

60 pertinent discussion on the feasibility of above technique in rainwater removal. This method is

61 however, relatively slow limited by safe travel speed of orchard sprayers (approx. $0.9 \mathrm{~m} \cdot \mathrm{s}^{-1}$ ). In

62 contrast, manned helicopters can fly at speeds of 2.3 to $4.5 \mathrm{~m} \cdot \mathrm{s}^{-1}$ above tree canopies to

63 remove/disperse rainwater off fruits and leaves using rotor downwash (Pihl, 2012). Such speeds

64 allow the coverage of acreage more quickly and hence are preferred by growers to remove

65 rainwater considering time-sensitive issues. However, seasonal helicopter rental costs and timely

66 availability of the helicopters are limiting factors. Additionally, low flying altitude and resulting

67 downwash of manned helicopters can cause damage to fruits and may also cause serious injury,

68 even death, to pilots. For example, in central Washington State alone, four fatal helicopter

69 crashes were reported during 2010 to 2014 (Wheat, 2014). 
To seek a safe and economical solution for rainwater removal from cherry tree canopies,

71 unmanned middle-size helicopters (UMHs, take-off weight more than $25 \mathrm{~kg}$ but less than $600 \mathrm{~kg}$,

72 categorized in Group 3 in Department of Defense UAS Groups [DoD, 2011]) are a possible

73 option. Such platforms may generate sufficient downwash with better altitude control in auto-

74 pilot assisted flights, provide pilot safety due to remotely controlled operations and may lower

75 operating costs in comparison to manned helicopters. Currently, UMHs are being used in

76 precision agriculture for low altitude remote sensing and targeted spray applications for pest and

77 disease control (Huang et al., 2013; Qiu et al., 2013; Sampson, 2014). More than 30\% of rice

78 acreage in Japan is being sprayed with such helicopters (Lan et al., 2010; Sampson, 2014).

79 Recent research efforts have been focused on determining the optimal spraying parameters of

80 such UMH platforms including flight altitude and travel speed for wheat (Bae and Koo, 2013;

81 Qiu et al., 2013) and other crops.

82 There are no studies reported on the applicability of UMHs on rainwater removal from

83 canopies to prevent fruit cracking. Therefore, the goal of this study was to evaluate the feasibility

84 of an UMH and pertinent operating parameters towards effective rainwater removal from cherry

85 tree canopies. The specific objectives were 1) to quantify the helicopter downwash in hover

86 above Y-trellised cherry tree canopies at different altitudes and payload conditions, and 2) to

87 evaluate efficacy of helicopter downwash under different flight altitudes, speeds and payload

88 conditions in rainwater removal from trees canopies.

89

90 2. Materials and Methods

912.1 Unmanned mid-size helicopter 
Sufficient downwash over and through tree canopies is the key requirement for successful rainwater removal applications. The velocity of downwash is determined by rotor diameter,

94 helicopter weight, and air density around rotors (Johnson, 2012). Downwash velocity directly

95 underneath the helicopter is defined as wake-induced downwash velocity, termed as downwash

96 henceforth, and can be estimated using equation 1 (Johnson, 2012; Shi, 2015):

$$
\omega=\sqrt{\frac{2 T}{\rho A}}
$$

98 where, $\omega$ is the wake-induced downwash $\left(\mathrm{m} \cdot \mathrm{s}^{-1}\right), T$ is the total thrust (equivalent to the weight of

99 helicopter, $N), A$ is the disk area $\left(\mathrm{m}^{2}\right)$ and $\rho$ is the air density $\left(1.2 \mathrm{~kg} \cdot \mathrm{m}^{-3}\right.$ at sea level). The UMH

100 used in this study was a remotely-piloted helicopter (RMAX, Yamaha Corp., Cypress, CA, USA)

101 designed for agriculture purposes (Fig. 1a). Specifications of the UMH are listed in Table 1.

102 Based on these attributes, estimated (theoretical) helicopter downwash with and without payload

103 (the $16.0 \mathrm{~kg}$ spray tanks filled with water) for the experimental helicopter was $13.5 \mathrm{~m} \cdot \mathrm{s}^{-1}$ and

$104 \quad 12.2 \mathrm{~m} \cdot \mathrm{s}^{-1}$, respectively.

105

106 Table 1: Specifications of the unmanned middle-size helicopter used in this study*

\begin{tabular}{cc} 
Parameters & Description \\
\hline Model & Yamaha RMAX \\
Empty weight (with fuel) & $64.0 \mathrm{~kg}$ \\
Sprayer weight & $7.4 \mathrm{~kg}$ \\
Spray tank (full) & $2 \times 8.0 \mathrm{~kg}$ \\
Main rotor diameter & $3.1 \mathrm{~m}$ \\
Overall length & $2.8 \mathrm{~m}$ \\
Overall width & $0.7 \mathrm{~m}$ \\
Overall height & $1.1 \mathrm{~m}$ \\
\hline
\end{tabular}

\footnotetext{
*Data were obtained from: www.yamahaprecisionagriculture.com.
} 

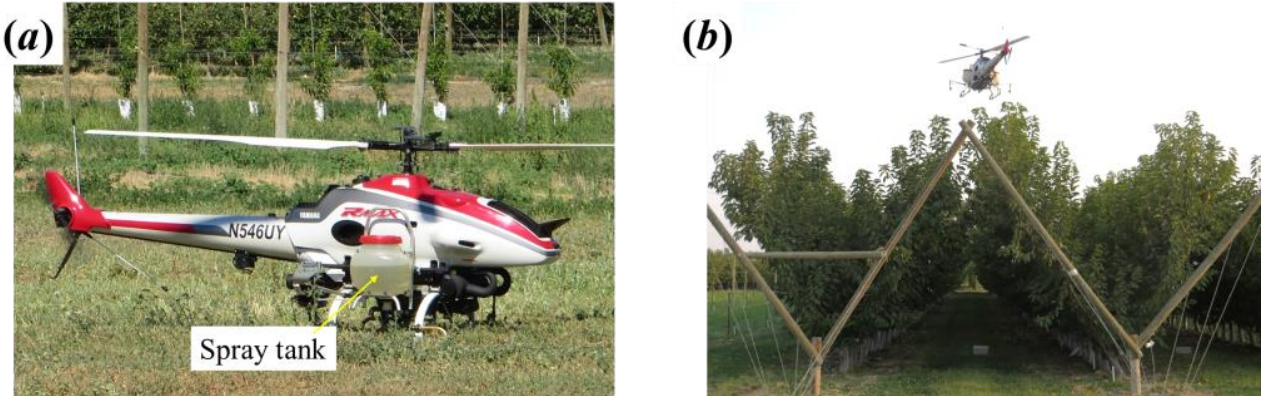

Fig. 1. (a) Unmanned middle-size helicopter (UMH) with detachable spray tank on either side; (b) Test trees were trained to Y-trellised canopy architecture. During field trails, the UHM was flying above the canopy at different altitudes and speeds.

\subsection{In-field sensing system}

An in-field sensing system was developed to monitor the leaf wetness, wind velocity and direction, temperature and humidity of cherry canopies. The sensing system consisted of data loggers (CR1000, Campbell Scientific, Logan, Utah, USA) and various sensors, including leaf wetness sensors (LWS, Decagon Device, Pullman, WA, USA), sonic anemometers (DS-2, Decagon Devices, Pullman, WA, USA), and temperature and humidity sensors (VP-3, Decagon Devices, Pullman, WA, USA). In the system, leaf wetness sensors (LWSs) were used to quantify the wetness level of tree canopies. LWSs quantify wetness level based on measuring the dielectric constant of the sensor upper surface, which is sensitive to moisture. Integrated with the conditioning circuit, the output voltage of a LWS is proportional to the surface wetness level (LWS Operation Manual, 2014). The wind velocity and direction was measured by 2D sonic anemometers, which have no moving parts and can be easily mounted in tree canopies. These sonic anemometers can measure wind velocity of up to $30.0 \mathrm{~m} \cdot \mathrm{s}^{-1}$ with an error of $\pm 0.3 \mathrm{~m} \cdot \mathrm{s}^{-1}$ at the maximum sample rate of $1 \mathrm{~Hz}$. The relative humidity $(\mathrm{RH})$ and temperature probe used in this system is a pre-calibrated, marine grade product. Probe error is in the ranges of $\pm 2.0 \%$ to $\pm 4.0 \%$ when used in the test orchard environment (temperature: 20.0 to $40.0^{\circ} \mathrm{C}, \mathrm{RH}: 10$ to $90 \%$ ). 
129 The temperature output has an error of less than $\pm 0.5^{\circ} \mathrm{C}$ while measuring temperature from 0.0 to $130 \quad 70.0^{\circ} \mathrm{C}$.

The excitation voltage for LWSs was provided by the CR1000 to accurately measure and

$132 \log$ the LWS data at frequency of $1 \mathrm{~Hz}$. Meanwhile, the anemometers' data were also recorded

133 by the data loggers at $1 \mathrm{~Hz}$ sample rate. The data loggers were configured and controlled through

134 LoggerNet ${ }^{\circledR}$ software (V4.3, Campbell Scientific, Logan, Utah, USA). The sampled data were

135 saved in the internal storage of the CR1000 and later copied to the hard drive of a laptop.

136 Communication between data loggers and laptop was through a serial port RS-232 or wireless

137 radio model RF401 (Campbell Scientific, Logan, Utah, USA). The sensing system was powered

138 using a 12 VDC lead-acid battery and was protected with a rugged and weather-proof enclosure.

2.3 Rainfall simulation system

A rainfall simulation system was developed to mimic different rainfall levels in orchard

142 condition. The system consisted of a water pumping system and a spray system (Fig. 2). To

143 provide consistent pressure water flow to nozzles, a centrifugal pump (1538, Hypro, New

144 Brighton, MN, USA) powered by a gas engine (GX 120, Honda Engines, Alpharetta, GA, USA)

145 were included in the pumping system. The water pumping system was mounted on an

146 agricultural vehicle (4210, Deere \& Company, Moline, IL, USA) and connected to a $0.2 \mathrm{~m}^{3}(55$

147 gallons) water tank through a manual valve used to regulate the water pressure. The spray system

148 consisted of eight sets of full cone spray tips (FCX80, Hypro, New Brighton, MN, USA). Each

149 nozzle had a cone angle of $80^{\circ}$ and output flow rate of $2.2 \times 10^{-5} \mathrm{~m}^{3} \cdot \mathrm{s}^{-1}$ at $275.0 \mathrm{kPa}$. The spray

150 tips were installed on a quick connect adaptor (QJ90-2-NYR, Teejet technologies, Wheaton, IL,

151 USA) which was fitted on a $2.5 \mathrm{~cm}$ inside diameter polyvinyl (PVC) hose through a check valve 
nozzle body at an interval of $0.3 \mathrm{~m}$. The PVC hose with nozzles was fitted to an aluminum structure and then mounted on a telescoping mast (LM20-S, Floatograph, Santa Barbara, CA, USA), which could raise the nozzle assembly up to 7.0 meters from ground surface. The mast was also mounted on an agricultural vehicle to improve the mobility of the rainfall simulation system. In the test, the nozzles were adjusted at 0.5 to $1.5 \mathrm{~m}$ above the top of the tree canopies according to the local wind condition, which allowed the artificial rainfall to cover 3.0 to 5.0 trees at one time (see Fig 2a).
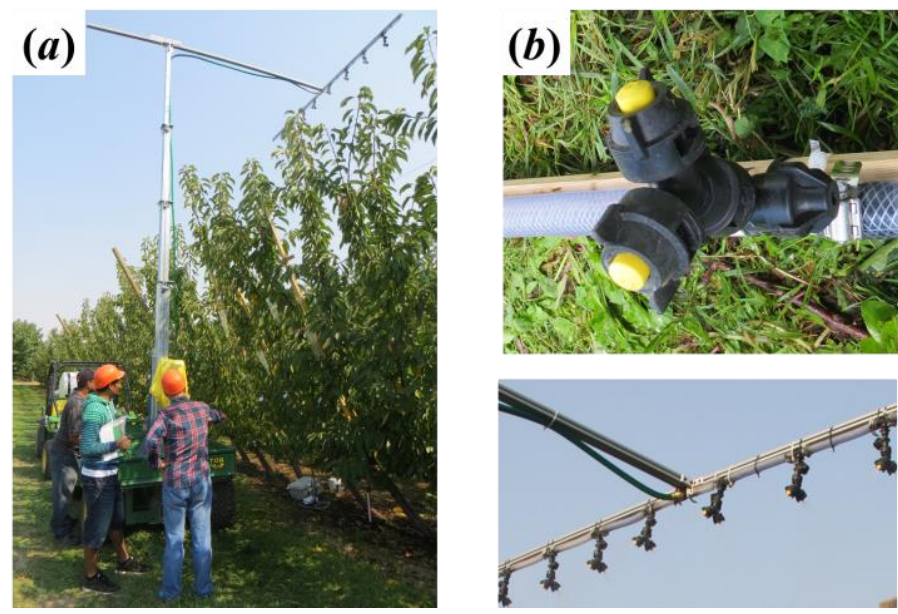

Fig. 2. (a) Rainfall simulation system and (b) configuration of nozzles sets. Two nozzle tips in a quick connector were $90^{\circ}$ from each other.

The coverage and discharge rate of the spray system was determined by the height and water pressure, respectively. With the fixed cone angle of the spray tips, the higher the nozzles were, the larger the area would be covered. In the trials, the pressure of the spray system was set at $200.0 \mathrm{kPa}$ and the height of spray system was set at approx. $5.0 \mathrm{~m}$ above the ground while generating different rainfall levels through counting operation time and checking readings of manual rain gauges.

2.4 Experimental orchard and treatment 

experimental orchard located at north of Prosser, WA, USA. According to the historical data

173 from WSU AgWeatherNet (www.weather.wsu.edu), the maximum daily rain levels were 18.3, 1747.9 and $7.4 \mathrm{~mm}$ in June, July and August, respectively, from 2008 to 2015. The test trees were 175 'Skeena' sweet cherry (Prunus avium L.) cultivar grown on Gisela ${ }^{\circledR} 6$ (Gi6) root stock, which 176 were trained as a Y-trellised fruiting wall canopy with branches on both sides growing at a $55^{\circ}$ 177 angle to the ground. The cherry trees were planted seven years ago (2009) with an inter-row and 178 intra-row spacing of $4.6 \mathrm{~m}$ and $0.9 \mathrm{~m}$, respectively. The average tree height was 3.2 to $4.0 \mathrm{~m}$ 179 above ground. The tree rows were orientated north to south with approx. 100 trees in each row. Experimental runs were conducted at cherry growth stage (BBCH stage) of the end of 8.9 to 181 stage 9.1 (Fadón et al., 2015), which were a few weeks after commercial harvesting window, i.e. 182 August, 2016. Trees had good vigor and leaves were green (see Fig. 2a).

2.4.1 Evaluation of helicopter downwash in hover weight, rotor diameter and flight altitude. The weight of the test UMH varied by adding or 187 removing the water tank with a weight of $16.0 \mathrm{~kg}$ full of water, which referred as condition of with and without payload in the following content. The hover or flying height of the UMH was adjusted by the pilot through a telemetry reading and position hold settings. In this study, four hover altitudes of 4.9, 5.5, 6.1 and $7.6 \mathrm{~m}$ above ground level (AGL) were evaluated. The 191 experimental setup of hover downwash evaluation was shown in Table 2. To measure the 192 downwash at different locations in the tree canopies, six 2D sonic anemometers were mounted 193 on different trees with four of them in the top section (3.1 m AGL) and two in the middle section 194 (2.1 m AGL), as shown in Fig. 3. The four anemometers were at the same height to measure the 
195 downwash on the top section of canopies and at adjacent locations in the horizontal direction.

196 The two lower anemometers measured the downwash transmitted through canopies. All

197 anemometers were wired to two data loggers, and their data were logged at $1 \mathrm{~Hz}$.

198

199

Table 2. Studied experimental parameters to evaluate of hover downwash of the UMH.

\begin{tabular}{ccc} 
Payload & Altitude $(\mathrm{m})$ & Hover time $(\mathrm{s})$ \\
\hline With & $4.9,5.5,6.1,7.6$ & $60-120$ \\
Without & $4.9,5.5,6.1,7.6$ & $60-120$ \\
\hline
\end{tabular}

200

201

202

203

204

205

206

207

208

209

210

211

212

213

214

215

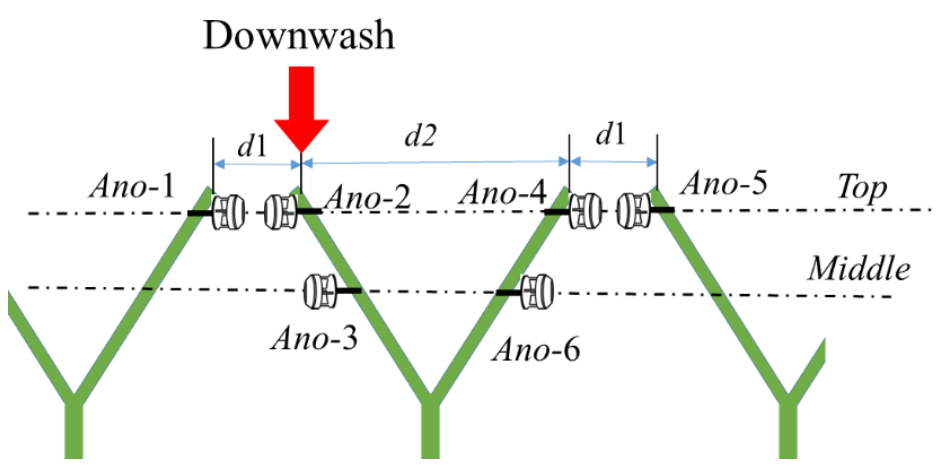

Fig. 3. Illustration of anemometers placement within the canopies to measure the hover downwash at different altitudes. In the figure, Ano-1 to Ano-6 indicate the mounting locations of six anemometers. Distances between anemometers were $d 1=1.2 \mathrm{~m}$ and $d 2=2.8 \mathrm{~m}$. Four anemometers (Ano-1, Ano-2, Ano-4 and Ano-5) were mounted in the top section of the canopies, which was $3.1 \mathrm{~m}$ above ground level. Two anemometers (Ano-3 and Ano-6) were at the middle section of the canopies, which was $2.1 \mathrm{~m}$ above ground level. The downwash center located above Ano-2, and the horizontal distance to Ano-1, Ano-4 and Ano-5 was 1.2, 2.8 and $4.0 \mathrm{~m}$, respectively.

\subsubsection{Rainwater removal efficacy evaluation}

To quantify canopy wetness due to rainwater and to monitor the micro-climate within the canopies, sensors were mounted on randomly selected branches of cherry trees to cover most of the canopy area as illustrated in Fig. 4. Three (3) LWSs were mounted at three heights of 1.1, 1.9, and $2.7 \mathrm{~m}$ above ground, henceforth referred as the bottom, middle and top LWS, along a 
randomly selected branch. To mimic tree leaves, LWSs were configured onto small branches

217 with the sensors facing up and tilting at $30^{\circ}$ to $45^{\circ}$ to the ground level. In each treatment, three

218 branches were selected as replicates and the data from nine LWSs were collected by a data

219 logger at a sample rate of $1 \mathrm{~Hz}$. An air humidity and temperature probe were also mounted in the center of the canopy section to monitor the variation during different treatments and its data were

221 also logged at $1 \mathrm{~Hz}$.

222

223

224

225

226

227

228

229

230

231

232

233

234

235

236

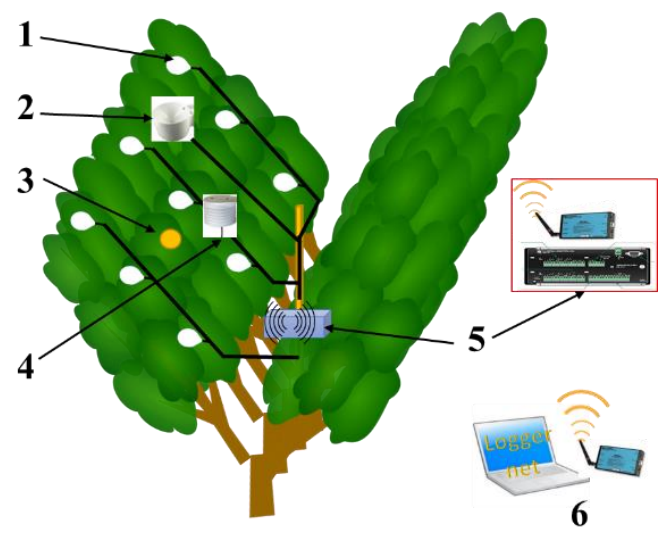

Fig. 4. Configuration of experimental system, including sensing and data logging system. The instrumentation and equipment include: 1 - leaf wetness sensors (nine in total); 2 - rain gauge; 3 - anemometer; 4 - temperature and humidity probe; 5 - data logger and radio module; 6 - Data logging with wireless receiver.

To evaluate rainwater removal efficacy of the $\mathrm{UMH}$, treatments were randomized in a complete block design (Table 3). The payload condition (with and without payload) was considered as a fixed effect, and the effects of flight altitude and travel speed were evaluated for their effectiveness in rainwater removal from tree canopies. Four groups of target trees (3 to 5 trees for each group) were randomly selected in one row, with one group serving as the control. Three other groups were used to evaluate downwash from different treatments, i.e. payload, flight altitude and travel speed, as shown in Table 3. In each treatment, 5.0-mm of rain was applied on the target canopies using the developed rainfall simulation system. The rainfall levels 
were monitored by timing and also through rain gauges distributed at different locations on target trees. After rainfall was applied, the UMH would fly over the top of target trees with respective treatment parameters in Table 3. Trees in control group were also applied same amount of rainwater of $5.0 \mathrm{~mm}$, but without downwash-based water removal.

Table 3. Studied experimental parameters to evaluate the efficacy of unamnned helicopter donwwash in rainwater removal.

\begin{tabular}{ccccc}
\hline \multirow{2}{*}{$\begin{array}{c}\text { Block (fixed } \\
\text { effect) }\end{array}$} & \multicolumn{2}{c}{ Treatment (random effect) } & Replicate & $\begin{array}{c}\text { Control } \\
\text { treatments }\end{array}$ \\
\cline { 2 - 3 } & $\begin{array}{c}\text { Helicopter } \\
\text { speed }\left(\mathrm{m} \cdot \mathrm{s}^{-1}\right)\end{array}$ & Altitude $(\mathrm{m})$ & & \\
\hline With payload & $1.3,2.7$ & $4.9,5.5,6.1$ & 3 & 5 \\
Without payload & $1.3,2.7$ & $4.9,5.5,6.1$ & 3 & 5 \\
\hline
\end{tabular}

The micrometeorological conditions recorded by the nearby in-field weather station (AgWeathernet WSU, Prosser, WA), included wind speed, wind direction, air temperature, and humidity, were $1.5 \pm 0.3$ (mean \pm std. dev.) $\mathrm{m} \cdot \mathrm{s}^{-1} \mathrm{NW}$ to $\mathrm{S}, 21.8 \pm 3.8^{\circ} \mathrm{C}$, and $39.5 \pm 8.0 \%$, respectively during the experiment period (7:00 am - 12:00 noon) on August, 2015.

\subsection{Data analyses}

The outputs of LWSs approximated the canopy wetness levels during each of the treatments. A typical sensor output is shown in Fig. 5, which illustrates the procedure of cherry canopy wetting and drying during an experimental run. Before rainfall, the outputs of LWSs were considered as 'dry' outputs $\left(V_{d}\right)$, which were the lowest values in each treatment. The outputs of LWSs would increase with more water falling on the sensing surface. However, since the surface of LWS could hold a limited amount of water and extra water would slip off the sensor, the LWS outputs would keep constant after a certain time (saturation). The saturation outputs were considered as 'wet' outputs $\left(V_{w}\right)$, which were the highest values of the LWS. Due to 
259 the systemic error of sensors and the variation of mounting angle, the wet outputs might be

260 different from sensor to sensor. To reduce the effect of LWS's reading variation, a normalized

261 parameter of canopy wetness $(C W, \%)$ was defined as the ratio of the difference between current

262 sensor output $\left(V_{r}\right)$ and dry output to the difference between the dry output and wet output,

263 calculated as:

264

$$
C W=\frac{V_{r}-V_{d}}{V_{w}-V_{d}} \times 100
$$

265 where, $V_{\mathrm{r}}$ is the arbitrary output of the sensor $(\mathrm{mV}), V_{d}$ and $V_{w}$ are dry and wet outputs $(\mathrm{mV})$ of 266 LWS.

267

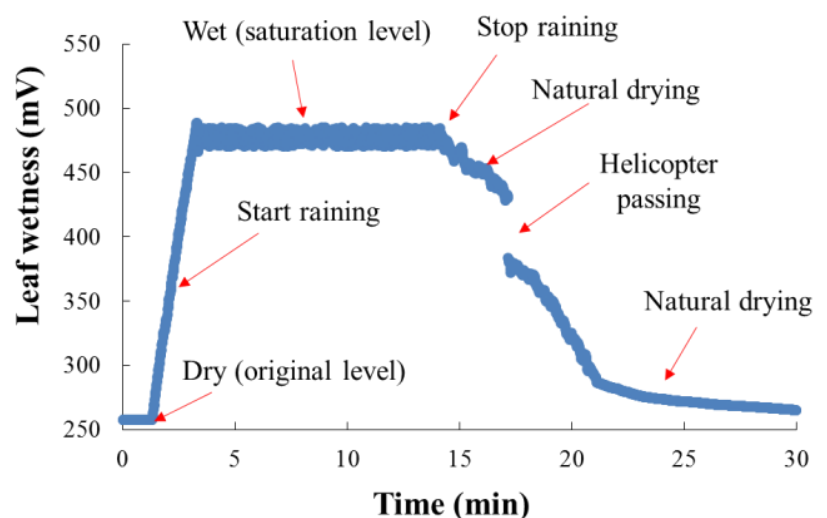

268

269

270

271

272

273

274 humidity and rainwater interception storage capacities (Huber and Gillespie, 1992). The

275 rainwater removal efficacy of an $\mathrm{UMH}$ in this research was quantified by rainwater removal

$276(R R, \%)$, which is the difference of canopy wetness between saturated condition $(C W=100 \%)$

277 and $C W$ at 10-min after the saturated canopy wetness. 
Pertinent data was analyzed in SAS $^{\circledR}$ (ver. 9.2, SAS Institute, Cary, NC, USA). Raw data

279 were plotted using box-and-whiskers plots, and outliers in the data were identified using the BOXSTYLE = SCHEMATICID option. Outliers were usually from sudden water drops from

281 other leaves in the drying process and they were removed for further statistical analysis. The

282 treatment effects were assessed using ANOVA ('PROC MIXED') analysis. In the hovering test, 283 the height of anemometer (top and middle of canopy) was considered as fixed effect, while the 284 payload and flight altitude were random effect. In rainwater removal test, payload was

285 considered as fixed effect (block), while flight altitude and travel speed were randomized factors.

286 The fixed effect was evaluated independently, while both the individual and interaction effect

287 were evaluated for random factors. The effect of sensor location on the rainwater removal was

288 analyzed to compare the difference in rainwater removal from different sections of canopies.

289 Least-squares mean difference ('LSMEANS/PDIFF') option was used to compare the treatments 290 at 0.05 level of significance. The output data were plotted using SigmaPlot ${ }^{(}$(ver. 11.0, Systat 291 Software, San Jose, CA, USA).

293 3. Results and Discussion

294 3.1 Evaluation of helicopter downwash in hover

295 Downwash generated by the UMH hovering at four altitudes of 4.9, 5.5, 6.1 and $7.6 \mathrm{~m}$

296 AGL was measured at two heights within the tree canopies. The effects of payload and hover 297 altitude on downwash were significant (Fig. 6). Overall effect of the location on the downwash 298 was significant with the average downwash on the top section of canopies (3.1 m AGL) was 299 significantly higher than that in the middle sections (2.1 m AGL) at each hover altitude $(p<0.01$ 300 in every treatment). Comparing to the downwash in the top section of the tree canopies, 
downwash in the middle section was reduced in the ranges of $37 \%$ to $50 \%$ and $25 \%$ to $46 \%$ for likely reduced by the tree branches, twigs and leaves in canopies.

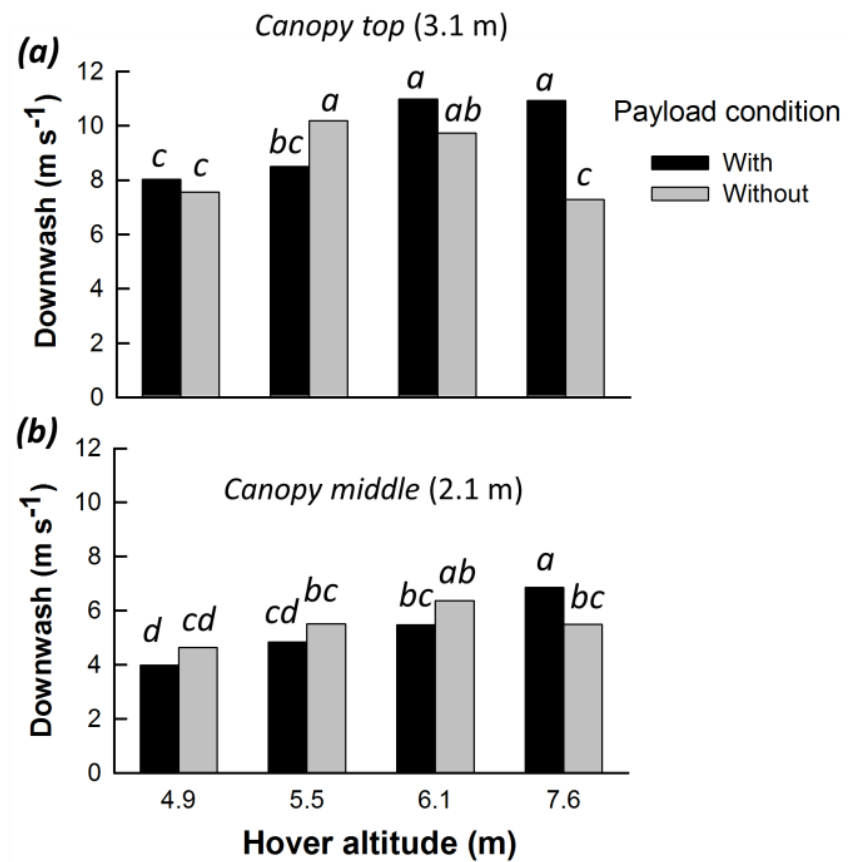

Fig. 6. Unmanned middle-size helicopter downwash in relation to the hover altitude above ground level (AGL) at with and without payload conditions. (a) Downwash measured at the top section of canopies (3.1 m AGL) and (b) Downwash measured at the middle section of canopies (2.1 $\mathrm{m}$ AGL). Small letters indicate the significance of the difference in downwash with different treatments at 0.05 level. There is no single effect of payload and hover altitude on downwash, while the interaction effect was significant $(p<0.001)$ in both figures.

Downwash varied significantly with different hover altitudes and payloads, which interactively affected the downwash (interaction effect $p<0.001$ ). From Fig. 6a one can find that the downwash at the top of the canopies increased from 8.0 to $10.9 \mathrm{~m} \cdot \mathrm{s}^{-1}$ as an UMH hover altitude increased from 4.9 to $7.6 \mathrm{~m}$ AGL with payload. However, when the payload was removed, the highest downwash was in the middle flight altitude of 5.5 and 6.1 m AGL, where the downwash was significantly higher than that of lowest and highest test altitudes of 4.9 and 7.6 m AGL. A similar downwash trend was evident at the middle section of canopies (Fig. 6b), where downwash with payload showed increasing trend as an UMH hover altitude increased 
320 above the ground level, whereas an UMH without payload had a peak downwash in the middle

321 of the test hover altitudes, again in an interactive effect $(p<0.001)$. Overall, the payload and

322 hover altitude affected the downwash as a mixed effect. Optimal hover altitude to generate the

323 highest downwash for the tested helicopter can be about $7.6 \mathrm{~m}$ with payload, and $5.5 \mathrm{~m}$ to $6.1 \mathrm{~m}$

324 without payload.

325 Downwash is affected by the diameter of helicopter rotors, which also determines the 326 coverage. Fig. 7 shows relationship of downwash at the top section of the canopies in horizontal 327 direction perpendicular to the nose of the helicopter. Compared to the center point, downwash 328 measured in the adjacent locations dropped substantially with the increase of distance regardless 329 of the hover altitude. As shown in Fig. 7, the measured downwash was as low as $0.3 \mathrm{~m} \cdot \mathrm{s}^{-1}$ at the 330 location of $2.8 \mathrm{~m}$ or farther away from center point. The location having downwash of $4.0 \mathrm{~m} \cdot \mathrm{s}^{-1}$ 331 might be about $1.3 \mathrm{~m}$ from center point at the hover altitude of $4.9 \mathrm{~m}$ if downwash was 332 considered as somewhat linear function of distance (as shown in Fig. 7). It indicated that the 333 diameter of covered area with the downwash of $4.0 \mathrm{~m} \cdot \mathrm{s}^{-1}$ or higher was approximately $(1.3 \times 2)$ $3342.6 \mathrm{~m}$. In this study, the canopy width of the test trees (with both sides) was approx. $2.8 \mathrm{~m}$, which 335 means that the UMH could cover one row with every pass. In Washington State, the cherry tree 336 canopy width with traditional architectures (central lead and multiple lead open center) is in the 337 range of 3.5 to $5.0 \mathrm{~m}$ (Ampatzidis and Whiting, 2013). However, for the modern trained 338 architectures (Y-trellised, upright fruiting offshoots [UFO], Kym Green Bush [KGB]), the 339 canopy width falls into the ranges of 0.3 to $3.5 \mathrm{~m}$ (Ampatzidis and Whiting, 2013). Therefore, 340 the test unmanned middle-size helicopter would be ideally suitable in modern orchards with 341 canopy width of about 3.0 m or less. 


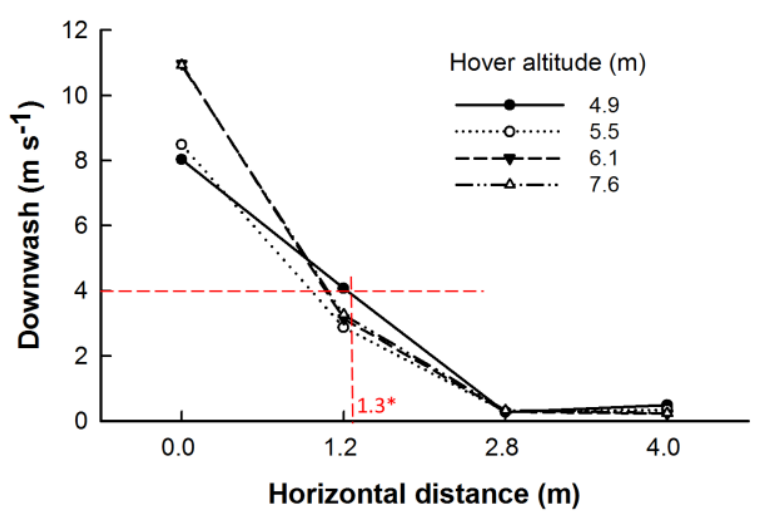

342

343

344

345

346

347

348

349

350

351

352

353

354

355

356

357

358

359

360

361

362

363

Fig. 7. Unmanned middle-size helicopter downwash measured in the top section of tree canopies at adjacent locations with payload. In the figure, 'Center' $(0.0 \mathrm{~m})$ locates in the top section of canopies (3.1 m AGL) and underneath the helicopter hover position. The number of $1.3^{*}$ was a calculated distance of having downwash of $4.0 \mathrm{~m} \cdot \mathrm{s}^{-1}$ based on linear interpolation between 1.2 and $2.8 \mathrm{~m}$ at the $4.9 \mathrm{~m}$ hover altitude. The adjacent locations in different trees are all at same height as the center point.

\subsection{Rainwater removal efficacy}

Rainwater removal efficacy of the UMH was quantified by rainwater removal (\%), which was analyzed using ANOVA to determine the significance of effect of payload, flight altitude and travel speed on the rainwater removal at 10-min after rain events. As discussed in experimental design and data analysis sections, the helicopter flight altitude and travel speed was randomized within the "blocks" of with payload and without payload. The effect of payload on rainwater removal was analyzed independently using all the data of rainwater removal from all locations. The results of ANOVA show that least-squares mean (LSMEAN) of the rainwater removal in all locations with payload was of $87.3 \%$, which was significantly higher than that of 83.2\% without payload ( $p=0.04)$. The flight altitude and travel speed interaction significantly affected on rainwater removal $(p=0.048)$. Fig. 8 shows the difference in the means of rainwater removal from tree canopies under different treatments and means of water removal of control groups. Fig. 8a shows the difference in the effect of the helicopter travel speed and flight altitude 
at the condition of with payload, where rainwater removal was significantly higher at the speed-

365 altitude combinations of 1.3-5.5, 1.3-6.1 and 2.7-6.1 $\left(\mathrm{m} \cdot \mathrm{s}^{-1}-\mathrm{m}\right)$ than other conditions, including control group. Within each travel speed, the UMH at the flight altitude of $6.1 \mathrm{~m}$ AGL removed more rainwater than that of lower altitude of $4.9 \mathrm{~m} \mathrm{AGL,} \mathrm{which} \mathrm{was} \mathrm{in} \mathrm{agreement} \mathrm{with} \mathrm{the} \mathrm{trend}$ that hover downwash at $6.1 \mathrm{~m}$ AGL with payload was significantly higher than that of at lower altitudes (Fig. 6a). Therefore, an UMH with payload at $6.1 \mathrm{~m}$ AGL and the preferred higher speed of $2.7 \mathrm{~m} \cdot \mathrm{s}^{-1}$ might be an ideal operation condition to remove rainwater from $\mathrm{Y}$-trellised

371 tree canopies.

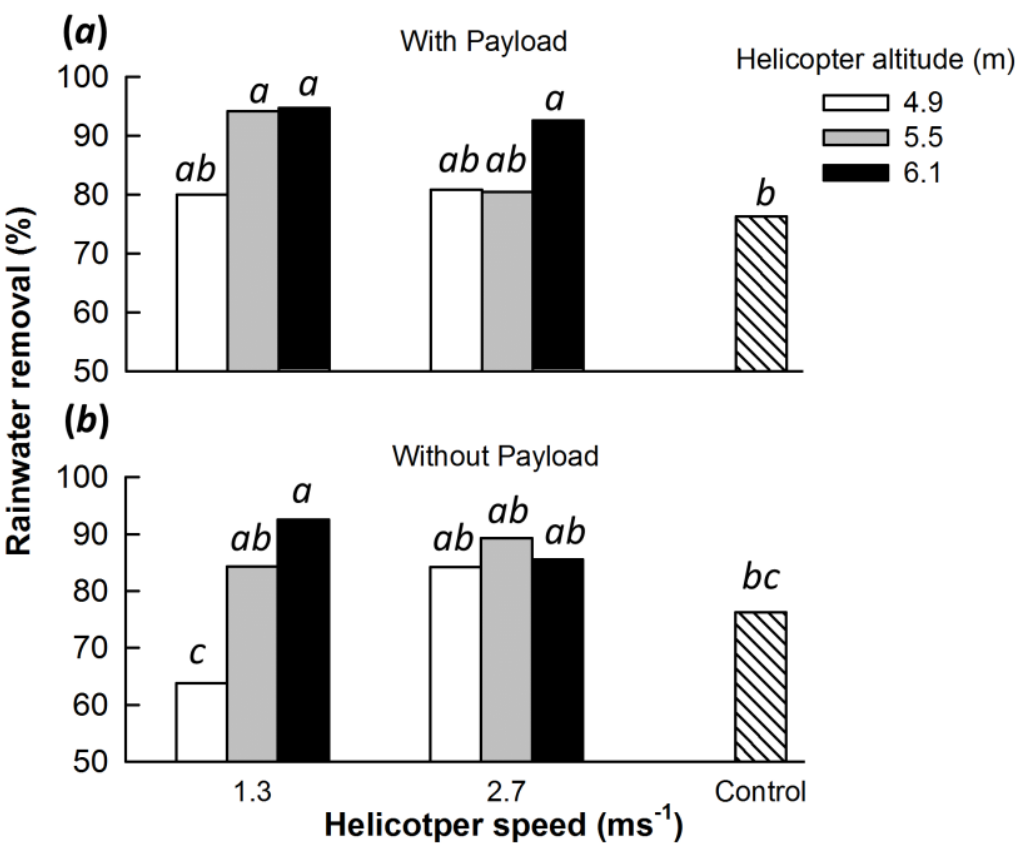

Fig. 8. Rainwater removal as a function of the helicopter flight altitude and travel speed under the condition of (a) with payload and (b) without payload. The figures show difference in the means of rainwater removal from all three locations of each treatment. The small letters indicate significant difference in the means of each treatment at 0.05 level.

Results pertinent to rainwater removal due to the UMH downwash without payload and at different travel speeds and flight altitudes are shown in Fig. 8b. Similarly with condition of with payload, interaction effect of flight altitude and travel speed was significant with $p=$ 
0.0001. Rainwater removal was significantly lower at the low altitude of $4.9 \mathrm{~m}$ and slow speed of $1.3 \mathrm{~m} \cdot \mathrm{s}^{-1}$ than that of the rest treatments. Considering the results from both with and without payload conditions, a high travel speed $\left(2.7 \mathrm{~m} \cdot \mathrm{s}^{-1}\right)$ and altitude $(6.1 \mathrm{~m})$ might have better performance in terms of effective rainwater removal from tree canopies. Considering LWS locations effect into the ANOVA, most of the interaction effects were not significant at 0.05 level. In this scenario, percent rainwater removal varied substantially (Table 4). Data showed that middle section of the canopies had significantly less rainwater removals compared to other two sections. It might be due to rainwater from top sections blown down to the middle sections due to downwash. Ground temperature and low canopy vigor at lower sections might have resulted in higher rate of water removal than that of middle sections. Further studies are needed to quantify this effect.

Table 4. Rainwater removal by the umanned helicotper under different treatements and locations. Payload was considered as fixed effect. The interaction of travel speed, flight altitude and sensor locations was analyzed. Different small letters, or different * indicate significant differences in the means of rainwater removal at $\mathbf{0 . 0 5}$ level. Bold numbers are significantly higher than italic numbers.

\begin{tabular}{|c|c|c|c|c|c|}
\hline \multirow{3}{*}{ Treatment } & \multirow{3}{*}{$\begin{array}{l}\text { Travel } \\
\text { speed } \\
\left(\mathrm{m} \cdot \mathrm{s}^{-1}\right)\end{array}$} & \multirow{3}{*}{$\begin{array}{l}\text { Flight } \\
\text { altitude } \\
\text { (m) }\end{array}$} & \multicolumn{3}{|c|}{ Rainwater removal (\%) (Mean \pm std. dev.) } \\
\hline & & & \multicolumn{3}{|c|}{ Sensor location } \\
\hline & & & Top $(2.7 \mathrm{~m})$ & Middle $(1.9 \mathrm{~m})$ & Bottom $(1.1 \mathrm{~m})$ \\
\hline \multirow[t]{3}{*}{ Control } & -- & -- & $71.2(18.6)^{a b^{* *}}$ & $81.4(12.1)^{a b^{* *}}$ & $77.1(20.2)^{a^{b * *}}$ \\
\hline & & 4.9 & $76.0(3.0)^{\mathrm{ab}}$ & $87.0(10.8)^{\mathrm{ab}}$ & $75.7(20.1)^{a b}$ \\
\hline & 1.3 & 5.5 & $93.3(3.6)^{a b}$ & $93.1(3.6)^{\mathrm{ab}}$ & $99.6(0.0)^{a}$ \\
\hline With & & 6.1 & $92.6(1.5)^{\mathrm{ab}}$ & $97.2(1.9)^{a}$ & $94.5(3.7)^{a b}$ \\
\hline \multirow[t]{5}{*}{ payload } & & 4.9 & $90.0(10.3)^{\mathrm{ab}}$ & $70.4(5.2)^{\mathrm{b}}$ & $82.1(4.7)^{a b}$ \\
\hline & 2.7 & 5.5 & $80.9(1.9)^{a b}$ & $73.6(1.6)^{b}$ & $90.4(0.1)^{a b}$ \\
\hline & & 6.1 & $96.3(2.4)^{a}$ & $87.6(3.2)^{\mathrm{ab}}$ & $92.1(1.3)^{\mathrm{ab}}$ \\
\hline & & 4.9 & $66.3(4.6)^{* *}$ & $62.6(11.9)^{* * *}$ & $63.2(18.6)^{* *}$ \\
\hline & 1.3 & 5.5 & $83.5(7.2)^{* *}$ & $87.1(11.5)^{* *}$ & $82.2(10.4)^{* *}$ \\
\hline Without & & 6.1 & $92.4(3.2) *$ & $94.5(5.5)^{*}$ & $90.6(10.2)^{*}$ \\
\hline \multirow[t]{3}{*}{ payload } & & 4.9 & $84.8(9.3)^{* *}$ & $84.1(0.6)^{* *}$ & $83.7(0.8)^{* *}$ \\
\hline & 2.7 & 5.5 & $90.3(8.5)^{*}$ & $87.0(4.2)^{* *}$ & $89.7(4.1)^{* *}$ \\
\hline & & 6.1 & $83.4(2.9)^{* *}$ & $84.0(9.3)^{* *}$ & $90.2(10.5)^{* *}$ \\
\hline
\end{tabular}


The coverage efficacy, defined as hectares of the area effectively covered by the

401 unmanned helicopter towards rainwater removal in one hour $\left(\mathrm{ha} \cdot \mathrm{h}^{-1}\right)$ is a key factor for growers.

402 In this study, we estimated coverage efficacy of the UMH by the coverage area per flight and its

403 travel speed. Considering the tree spacing of the test orchard of $4.6 \mathrm{~m} \times 0.9 \mathrm{~m}$, about 2391 trees

404 per hectare have to be treated for rainwater removal. Assuming an UMH was flown at the speed

405 of 1.3 to $2.7 \mathrm{~m} \cdot \mathrm{s}^{-1}$, the rainwater removal efficacy (coverage efficacy) would be 2.2 to $4.5 \mathrm{ha} \cdot \mathrm{h}^{-1}$.

406 For an orchard air-blast sprayer, the safe travel speed is about $0.9 \mathrm{~m} \cdot \mathrm{s}^{-1}$ leading to a coverage

407 efficacy of $1.5 \mathrm{ha} \cdot \mathrm{h}^{-1}$. Meanwhile, a manned helicopter can fly at the speed of $4.5 \mathrm{~m} \cdot \mathrm{s}^{-1}$ or less

408 and can cover two to three rows at one pass, resulting in the coverage efficacy of $7.5 \mathrm{ha} \cdot \mathrm{h}^{-1}$ in the

409 test orchard. However, outside of safety concerns, manned helicopter rentals are very expensive,

410 which is beyond the reach of small to mid-size $(<81$ ha) growers. Overall, an unmanned middle-

411 size helicopter that can remove the rainwater and also be used for other precision agricultural

412 application, may be an alternative in such scenario. In coming season, our team plans to

413 specifically evaluate efficacy of manned helicopters in rainwater removal from cheery canopies.

414 More studies at different rainfall levels and relating rainwater removal to fruit cracking are

415 needed along with detailed economic analysis to fully understand the operational feasibility of

416 such platforms for commercial operations.

418 4. Conclusions

419 Towards effective and economical rainwater removal from cherry tree canopies, an

420 alternative technology of an unmanned middle-size helicopter was evaluated for the first time.

421 An in-field sensing system was developed to quantify the downwash of the test helicopter at

422 different hover altitudes and payload conditions. Rainwater removal efficacy of the helicopter 
423 was quantified at different payloads, flight altitudes and travel speeds. Based on the results, the 424 following are concluded from the study:

425

426

427

428

429

430

431

432

433

434

435

436

437

438

439

440

441 442 WA.

443

444

445

446

(1) Downwash generated by the test helicopter might be significantly affected by payload and flight altitude. Downwash increased from 8.0 to $10.9 \mathrm{~m} \cdot \mathrm{s}^{-1}$ with the hover altitude increasing from 4.9 to $7.6 \mathrm{~m}$ at the condition of with payload. At the condition of without payload, the peak downwash of $10.2 \mathrm{~m} \cdot \mathrm{s}^{-1}$ was at the altitude of $6.1 \mathrm{~m}$ above ground level, while downwash was around $7.4 \mathrm{~m} \cdot \mathrm{s}^{-1}$ at altitude of 4.9 and $7.6 \mathrm{~m}$.

(2) Rainwater removal efficacy by an UMH downwash was significantly affected by the interaction of flight altitude and travel speed. Pertinent to studied flight attributes, a combination of a 6.1-m flight altitude AGL with a $2.7-\mathrm{m} \cdot \mathrm{s}^{-1}$ travel speed generated downwash either with or without payload that had significantly higher rainwater removal and coverage efficacy compared to other treatment combinations.

\section{Acknowledgements:}

This project was funded in part by WSU CHANRS Emerging Research Issues grant program and USDA National Institute for Food and Agriculture Project \# WNP00745. We thank CPAAS colleagues especially Dr. Manoj Karkee, Mr. Patrick Scharf, Mr. Haitham Bhalol, Dr.

Gopi Kafle, and Dr. Parish Nalwade for help during the field tests. We also acknowledge support of Yamaha Inc. (Precision Ag group), CA; Digital Harvest Inc., VA and Decagon Devices Inc.,

\section{Reference}

Ampatzidis, Y. G., Whiting, M. D, 2013. Training system affects sweet cherry harvest efficiency. Hortscience 48(5), 547-555. 
447 Bae, Y., and Koo, Y., 2013. Flight attitudes and spray patterns of a roll-balanced agricultural unmanned helicopter. Applied engineering in agriculture 29(5), 675-682.

Børve, J., Skaar, E., Sekse, L., Meland, M., Vangdal, E., 2003. Rain protective covering of sweet cherry trees - Effects of different covering methods on fruit quality and microclimate. HortTechnology 13(1), 143-148.

Cline, J. A., Meland, M., Sekse, L., Webster, A. D., 1995. Rain cracking of sweet cherries: II. Influence of rain covers and rootstocks on cracking and fruit quality. Acta Agriculturae Scandinavica, Section B - Soil \& Plant Science 45(3), 224-230.

Considine, J., Brown, K., 1981. Physical aspects of fruit growth theoretical analysis of distribution of surface growth forces in fruit in relation to cracking and splitting. Plant Physiology 68(2), 371-376.

DoD, 2011. Department of Defense (DoD) Unmanned Aircraft System Airspace Integration Plan (ver. 2). Available at: www.acq.osd.mil. Accessed on 10 Sept. 2015.

Fadón, E., Herrero, M., Rodrigo, J., 2015. Flower development in sweet cherry framed in the BBCH scale. Scientia Horticulturae 192(2015), 141-147.

Huang, Y., Thomson, S. J., Hoffmann, W. C., Lan, Y., Fritz, B. K., 2013. Development and prospect of unmanned aerial vehicle technologies for agricultural production management. International Journal of Agricultural and Biological Engineering 6(3), 110.

Jedlow, L. K., Schrader, L. E., 2005. Fruit cracking and splitting. In Pacific Northwest Fruit School Cherry Shortcourse Proceedings. Chapter 10, pp.65-66.

Johnson, W., 2012. Helicopter theory. Courier Corporation. 
Kafle, G. K., Khot, L. R., Zhou, J., Bahlol, H. Y., Si, Y., 2016. Towards precision spray applications to prevent rain-induced sweet cherry cracking: understanding calcium washout due to rain and fruit cracking susceptibility. Scientia Horticulturae. (In review)

Kaiser, C., Fallahi, E., Meland, M., Long, L. E., Christensen, J. M., 2014. Prevention of sweet cherry fruit cracking using sureseal, an organic biofilm . Acta Hortic (1020), 477-488.

Lan, Y., Thomson, S. J., Huang, Y., Hoffmann, W. C., Zhang, H., 2010. Current status and future directions of precision aerial application for site-specific crop management in the USA. Computers and Electronics in Agriculture 74(1), 34-38.

LWS Operation Manual, 2014. Dielectric leaf wetness sensor operator's manual. Decagon Devices, Pullman, WA.

Meland, M., Kaiser, C., Christensen, J. M., 2014. Physical and chemical methods to avoid fruit cracking in cherry. AgroLife Scientific Journal 3(1), 177-183.

Pihl, K., 2012. Copters called in to dry Tri-City cherries. Tri-city Herald 3 June, 2012. Available at: www.tri-cityherald.com. Accessed 10 Oct. 2014.

Qiu, B., Wang, L., Cai, D., Wu, J., Ding, G., Guan, X., 2013. Effects of flight altitude and speed of unmanned helicopter on spray deposition uniform. Transactions of the Chinese Society of Agricultural Engineering 29(24), 25-32.

Sampson, P., 2014. Drone helicopters for spraying crops. Available at: www.homediystuff.com. Accessed 10 Oct. 2015.

Shi, Q., 2015. Numerical simulation for downwash flow field of small-size unmanned helicopter hedgehopping. Journal of Drainage and Irrigation Machinery Engineering 33(6), 521525. 
491 Simon, G., 2006. Review on rain induced fruit cracking of sweet cherries (Prunus avium L.), its

492

493

494

495

496

497

498

499

500

501

502

503

504

505

506

507

508

509

510 causes and the possibilities of prevention. International Journal of Horticultural Science 12(3), 27-35.

Thomidis, T., Exadaktylou, E., 2013. Effect of a plastic rain shield on fruit cracking and cherry diseases in Greek orchards. Crop Protection 52(2013), 125-129.

USDA-NASS, 2015. Noncitrus Fruits and Nuts: 2014 Preliminary Summary. National Agricultural Statistics Service Database. Washington, D.C.: USDA National Agricultural Statistics Service. Available at: www.nass.usda.gov. Accessed 23 September 2015.

Vittrup Christensen, J., 1995. Rain-induced cracking of sweet cherries: Its causes and prevention. Cherries: Crop Physiology, Production and Uses. Ed. N. Looney \& A. Webster. CAB International, 297-327.

Wang, Y., and Long, L. E., 2015. Physiological and biochemical changes relating to postharvest splitting of sweet cherries affected by calcium application in hydrocooling water. Food Chemistry 181(2015), 241-247.

Wheat, D., 2014. Fourth cherry chopper crash in four years. Available at: www.capitalpress.com. Accessed on: 10 Oct. 2014.

Zhou, J., Khot, L., Bahlol, H. Y., Kafle, G. K., Peters, T., Whiting, M. D., Zhang, Q., Granatstein, D., 2016. In-field sensing for crop loss management: efficacy of air-blast sprayer generated crosswind in rainwater removal from cherry canopies. Computers and Electronics in Agriculture. (In review) 